\title{
Automated Non-invasive Skin Cancer Detection using Dermoscopic Images
}

\author{
Shruti Kale ${ }^{1}$, Reema Kharat ${ }^{2}$, Sagarika Kalyankar $^{3}$, Sangita Chaudhari ${ }^{4}$, Apurva Shinde $^{5}$ \\ ${ }^{1}$ Dept. of Computer Engineering, Ramrao Adik Institute of Technology, Nerul, Navi Mumbai \\ ${ }^{2}$ Dept. of Computer Engineering, Ramrao Adik Institute of Technology, Nerul, Navi Mumbai \\ ${ }^{3}$ Dept. of Computer Engineering, Ramrao Adik Institute of Technology, Nerul, Navi Mumbai \\ ${ }^{4}$ Dept. of Computer Engineering, Ramrao Adik Institute of Technology, Nerul, Navi Mumbai \\ ${ }^{5}$ Dept. of Computer Engineering, Ramrao Adik Institute of Technology, Nerul, Navi Mumbai
}

\begin{abstract}
Skin Cancer is resulting from the growth of the harmful tumour of the melanocytes the rates are rising to another level. The medical business is advancing with the innovation of recent technologies; newer tending technology and treatment procedures are being developed. The early detection of skin cancer can help the chance of increase in its growth in other parts of body. In recent years, medical practitioners tend to use non invasive Computer aided system to detect the skin cancers in early phase of its spreading instead of relying on traditional skin biopsy methods. Convolution neural network model is proposed and used for early detection of the cancer, and it type. The proposed model could classify the dermoscopic images into correct type with accuracy $91.2 \%$.
\end{abstract}

Keywords- tumour, melanocytes, medical practitioners, non-invasive, biopsy, dermoscopic.

\section{Introduction}

Skin Cancer rates are rising to another level. In 2018, 287,723 new incidents were reported according to intervals the planet and so the vary of deaths happened because of skin cancer is 60,712 . at intervals the U.S.A., almost 96,480 new malignant skin cancers area unit aiming to be identified. The harsh UV radiation from the Sunlight affects melanoma. Malignant melanomas invariably tend to unfold into surroundings but if treated at its early-stage dangers can be avoided. Therefore, early identification and treatment of skin cancer is particularly important and crucial task. Generally, in automated system it can be done in two parts: (1) Preprocessing of input and effective feature extraction and (2) Accurate classification of the image.

Skin cancer is the irregular growth of skin cells and its most frequently grows on skin exposed to the sun. But this form of cancer can also happen on areas of your skin not normally unprotected to sunlight. Skin cancer is broadly categorised into Basal Cell Carcinoma (BCC), Squamous Cell Carcinoma (SCC) and Melanoma Skin
Cancer (MSC). BCC is because of skin openness particularly found in the sun uncovered regions like the face, head, neck, arms, and legs. SCC is the disease of keratinocyte cells found on the external surface of the skin. It seems like a red firm knocks layered patches. Melanoma emerges from melanocytes, specific pigmented cells that are discovered. Risk can be reduced by preventive or avoiding revelation to ultraviolet (UV) radiation. Inspecting skin for doubtful changes can help to detect skin cancer at its earliest along with some computer aided diagnosis system. Early detection of skin cancer is an important step toward its fast growth in other parts of the body. Early detection of cancers and its type can be detected by dermatologists with the help of computer aided system. Thus, the objective of this paper is to construct a Computer Aided Diagnosis system that assists medical professionals detect skin cancer without the need of any expensive tools.

\section{Related Works}

About 1 million cases of non-cancerous and 288,000 of cancerous cases have been detected in 2018 . The impact

\footnotetext{
* Corresponding author: reema97.kharat@gmail.com
} 
of biological theory on continuation and value more stress the previously exhaust aid structure and lift the query of economic property. Carcinoma and particularly metric linear unit early spotting is difficult for each dermatologists. Dermatoscope is reserved into version the excellence of care, however in objective test dermatologist come through a restricted diagnostic sensitivity of 400 metric linear unit detection Thanks to the quality of graphic ideas rooted in an exceedingly dermoscopic image. General doctors appear to profit from use of a dermoscopic course, whereas several 51 accurately diagnosed lesions necessitate more enhancements. Likewise, specificity of diagnosing by dermatologists necessitate an extra improvement, as mirrored by a range of 28:1 to 9:1 variety of operations that require to be removed to spot one skin cancer and a 3:1 magnitude relation for general carcinoma.

Deep learning (DL) classifiers area unit an auspicious applicant for discovery of different types of skin cancers.
With al, laboratory studies reportable a clinical sensitivity, a difference which could be credited to the standard of the dataset input, thus version knowledge as new. Lately, a primary potential scientific empiric education reportable on a 2-step method, count a second layer of sonification (visual information was noises) to a decilitre classifier to enhance accuracy of detection. This twin decilitre utilised a sophisticated dermoscope, a comparatively dear device, and a way extremely keen about medico expertise translation it fewer appropriate for extensive medical care doctor's use. Accordingly, the influence of copy superiority on correctness of diagnosing has been suspected. It had been determined to check a cheap device secret by its builder as a skin scientific instrument with polarized lightweight (SMP). Picture's quality paternal by SMP preclude in most cases a particular clinical diagnosing thanks to haziness and lack of fine high level dermoscopic patterns and diagnostic structures. Table 2.1 shows summary of existing approaches.

Table 2.1: Survey of Existing Systems

\begin{tabular}{|c|c|c|c|c|c|}
\hline Authors & $\begin{array}{l}\text { Image } \\
\text { Acquisition }\end{array}$ & $\begin{array}{l}\text { Image Pre- } \\
\text { processing }\end{array}$ & $\begin{array}{l}\text { Image } \\
\text { Segmentation }\end{array}$ & Feature extracted & Classification \\
\hline $\begin{array}{l}\text { Ichim and } \\
\text { Popescu } \\
\text { [3] }\end{array}$ & ISIC and $\mathrm{PH} 2$ & $\begin{array}{l}\text { Elimination of } \\
\text { noise, Dull Razor } \\
\text { hair removal, } \\
\text { contrast and } \\
\text { normalisation }\end{array}$ & - & $\begin{array}{l}\text { Texture features, shape and } \\
\text { colour features }\end{array}$ & $\begin{array}{l}\text { Neural network, Back } \\
\text { propogation, } \\
\text { AlexNet and ResNet }\end{array}$ \\
\hline $\begin{array}{l}\text { Demyanov } \\
\text { et al. [4] }\end{array}$ & ISIC & - & - & $\begin{array}{l}\text { K Means clustering and sparse } \\
\text { coding with visual features } \\
\text { from Dense SIFT and SURF }\end{array}$ & $\begin{array}{l}\text { SVM with RBF } \\
\text { Kernel and CNN }\end{array}$ \\
\hline $\begin{array}{l}\text { Majumder } \\
\text { and } \\
\text { Ullah[5] }\end{array}$ & PH2 Dataset & $\begin{array}{l}\text { Dull-Razor algo- } \\
\text { to remove dark } \\
\text { hair from images. } \\
\text { Median filter is } \\
\text { also applied }\end{array}$ & $\begin{array}{l}\text { Otsu's } \\
\text { thresholding } \\
\text { method }\end{array}$ & $\begin{array}{l}\text { Asymmetry score across } \mathrm{x} \text { and } \\
\mathrm{y} \text {-axis, Area/perimeter ratio, } \\
\text { Compactness index, Average } \\
\text { diameter of lesion }\end{array}$ & $\begin{array}{l}\text { ANN with } \\
\text { backpropagation } \\
\text { algorithm }\end{array}$ \\
\hline $\begin{array}{l}\text { Jain et } \\
\text { al.[6] }\end{array}$ & PH2 Dataset & $\begin{array}{l}\text { Image resizing } \\
\text { and contrast } \\
\text { adjustment. } \\
\text { Applied } \\
\text { averaging filter to } \\
\text { RGB input } \\
\text { image. }\end{array}$ & $\begin{array}{l}\text { Otsu's } \\
\text { thresholding } \\
\text { method is } \\
\text { applied }\end{array}$ & $\begin{array}{l}\text { Asymmetry score across } \mathrm{x} \text { and } \\
\mathrm{y} \text {-axis, ABCD features, } \\
\text { variegation and lesion diameter } \\
\text { variation }\end{array}$ & $\begin{array}{l}\text { Backpropagation } \\
\text { Neural Network } \\
(\mathrm{BNN})\end{array}$ \\
\hline $\begin{array}{l}\text { Eltayef et } \\
\text { al.[7] }\end{array}$ & $\begin{array}{l}2008 \text {-bit RGB } \\
\text { color images with } \\
\text { a resolution of } \\
768 * 560\end{array}$ & $\begin{array}{l}\text { Directional Gabor } \\
\text { filters are } \\
\text { implemented to } \\
\text { extract the hairs }\end{array}$ & $\begin{array}{l}\text { Fuzzy c-means } \\
\text { and MRF is } \\
\text { used }\end{array}$ & $\begin{array}{l}\text { Asymmetry, border, Color } \\
\text { variegation and lesion diameter }\end{array}$ & Not specified \\
\hline $\begin{array}{l}\text { Isasi et } \\
\text { al.[8] }\end{array}$ & $\begin{array}{l}40 \text { RGB OF } \\
500 \times 500 \text { pixels } \\
\text { image catalogue } \\
\text { by certified } \\
\text { dermatologistes }\end{array}$ & $\begin{array}{l}\text { Pattern } \\
\text { recognition - } \\
\text { globular }\end{array}$ & $\begin{array}{l}\text { Globular, } \\
\text { Recticular and } \\
\text { blue-vein }\end{array}$ & $\begin{array}{l}\text { ABCD feature alongwith } \\
\text { features extracted from pattern } \\
\text { recognition algo. }\end{array}$ & $\begin{array}{l}\text { Classification is done } \\
\text { by ABCD rule }\end{array}$ \\
\hline $\begin{array}{l}\text { She et } \\
\text { al.[9] }\end{array}$ & Not specified & $\begin{array}{l}\text { High pass } \\
\text { filtering and } \\
\text { gradients } \\
\text { application }\end{array}$ & $\begin{array}{l}\text { Snake-based } \\
\text { detection } \\
\text { technique is } \\
\text { used to } \\
\text { determine lesion } \\
\text { boundry }\end{array}$ & $\begin{array}{l}\text { Asymmetry score across } \mathrm{x} \text { and } \\
\mathrm{y} \text {-axis, Area/perimeter ratio, } \\
\text { Compactness index, Average } \\
\text { diameter of lesion. }\end{array}$ & $\begin{array}{l}\text { Principal component } \\
\text { analysis is used for } \\
\text { classification }\end{array}$ \\
\hline
\end{tabular}




\section{Proposed System}

Various attempts made by researchers to detect skin cancer in its early stage using image processing techniques, machine learning and deep learning techniques. As the problem of existing system was that the output was not accurate. Even if it's cancerous cell it was detected as non-cancerous or vice-vera. System Flow Diagram predicting malignant lesions is depicted in figure 3.1. It consists of four steps: (1) image preprocessing; (2) image segmentation; (3) feature extraction; (4) classification. The input image can have noise and other artefacts such as hairs, air bubbles, varied colour, and textures of the skin. To get rid of these factors, pre-processing need to be applied on input image before passing it to segmentation or feature extraction phase so that eventually classifier can classify these input lesions in correct classifications as malignant or benign and the type of cancer.

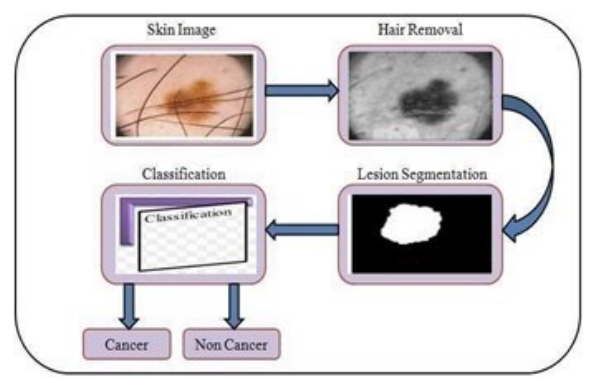

Figure 3.1: Skin Cancer Detection Process

In our proposed system, we are utilising modified Convolutional Neural Network (CNN). CNN consist of sequence of several convolutional layer with filters, pooling layers, fully connected layer. Convolutional layer is the initial layer which extract feature from an image. Pooling layers minimize the size of the activation map. Fully connected layer operates on a flattened input where each input is connected to all neurons. Figure 3.2 shows architecture of CNN.

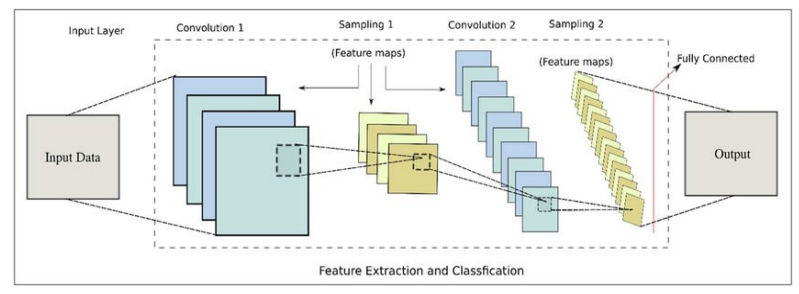

Figure 3.2: CNN Architecture

CNNs are convolution neural networks that are appeared to be terribly strong in areas like image recognition and classification. CNNs area unit a supervised learning technique and area unit thus instruct victimisation knowledge tagged with the various categories. primarily, CNNs grasp the link in the middle of the input items and the category tags and contains 2 elements: the invisible layers during which the options area unit drawn out and, at the top of the process, the totally connected layers that area unit used for the classification task. not like regular neural networks, the hidden layers of a $\mathrm{CNN}$ have a particular design. In regular neural networks, every layer is made by a collection of vegetative cells and one vegetative cell of a layer is connected to every neuron of the previous layer. The design of hidden layers in a very $\mathrm{CNN}$ is slightly completely different.

This restriction to native connections and extra merge layers sums up native vegetative cell product into one worth leads to Translation in variant options. This leads to an easier coaching procedure and a lower model quality. Figure 3.3 shows the steps followed in the proposed system. Data: Data is extracted for analysis towards skin cancer. In our project we have used over 8000 images. To test our system.

Data Visualization: It is a graphical presentation of knowledge of data. By applying perceptible segments like charts, graphs, maps to provide an approachable way to see and acknowledge direction, outliers, and patterns in data.

Image Pre-Processing: Is a procedure of making the rare information and creation it appropriate for a machine learning model. A filter is used to enhance the objects such as hair, marks in bright background.

CNN: Over here the system predicts if the image is cancerous or not, and if its cancerous then it predicts which type of cancer it is.

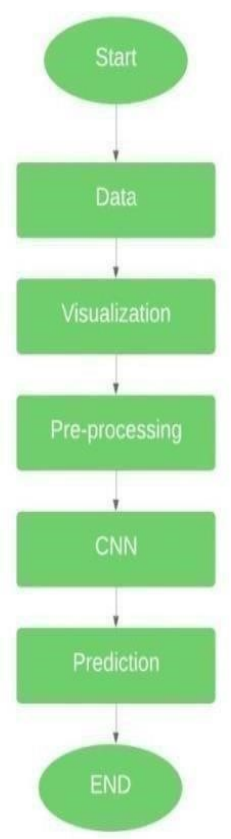

Figure 3.3: Flowchart for Proposed System

Performance Metrics for classifiers: A classifier set apart every object to a category. This piece of work is mostly not excellent, and entity is also assigned to the incorrect category to gauge the classification quality, the category - the category allocated by the classifier is likened with the class. this permits the substances to be alienated into the subsequent four subsections:

1. True positive (TP): Positive Class.

\footnotetext{
* Corresponding author: reema97.kharat@gmail.com
} 
2. True negative (TN): Negative Class.

3. False positive (FP): Incorrect Positive Class.

4. False Negative (FN): Incorrect Negative Class.

\section{Results and Discussion}

The diagnostic system proposed in this work has been implemented in Python. To testing the system, a dataset of approximately 10000 dermoscopic images from $\mathrm{PH}^{2}$ dataset are considered including mixed lesion images for Benign keratosis, melanocytic nevi, dermatofibroma, melanoma, vascular lesions, basal cell carcinoma, actinic keratoses [10].

The system could correctly classify the images as 'Benign' or 'Malignant' as well as the type of skin cancer as BCC, SCC or MSC. Figure 4.1 shows the sample statistics for different dermoscopic images. Figure 4.2 shows sample images for various types of skin cancer. Figure 4.3 and 4.4 shows localization and characteristics of lesion for some sample input images.

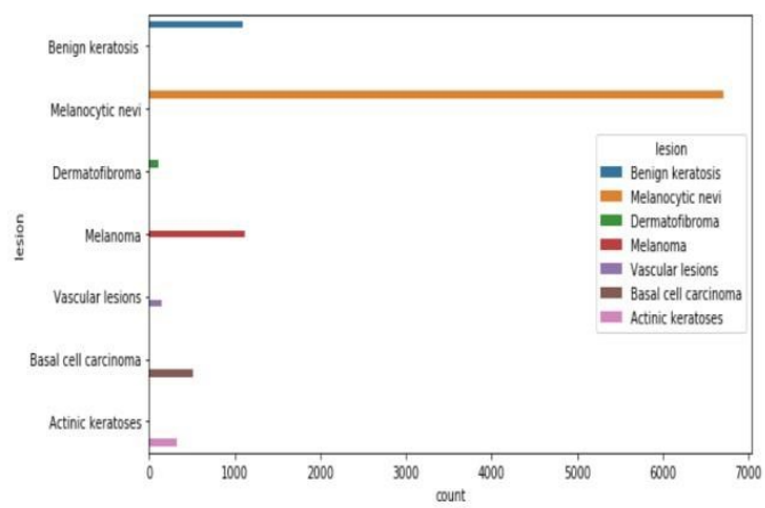

Figure 4.1: Satistics of dermoscipic images used in experimentation

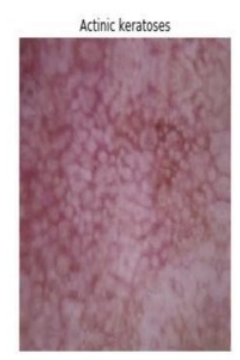

Melanocyic nevi

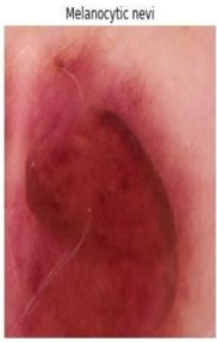

Figure 4.2 : Skin cancer dermoscopic image

\begin{tabular}{|c|c|c|c|c|c|c|c|}
\hline & lesion_id & image_id & $d x$ & dx_type & age & $\operatorname{sex}$ & localization \\
\hline 0 & HAM_0000118 & ISIC_0027419 & bkl & histo & 80.0 & male & scalp \\
\hline 1 & HAM_0000118 & ISIC_0025030 & $b k l$ & histo & 80.0 & male & scalp \\
\hline 2 & HAM_0002730 & ISIC_0026769 & $b k l$ & histo & 80.0 & male & scalp \\
\hline 3 & HAM_0002730 & ISIC_0025661 & $\mathrm{bkl}$ & histo & 80.0 & male & scalp \\
\hline 4 & HAM_0001466 & ISIC_0031633 & bkl & histo & 75.0 & male & ear \\
\hline
\end{tabular}

Figure 4.3: Localization of lesions

\begin{tabular}{|c|c|c|c|c|c|c|c|c|}
\hline & lesion_id & image_id & $d x$ & dx_type & age & sex & localization & lesion \\
\hline 0 & HAM_0000118 & ISIC_0027419 & $\mathrm{bkl}$ & histo & 80.0 & male & scalp & Benign keratosis \\
\hline 1 & HAM_0000118 & ISIC_0025030 & bkl & histo & 80.0 & male & scalp & Benign keratosis \\
\hline 2 & HAM_0002730 & ISIC_0026769 & bkl & histo & 80.0 & male & scalp & Benign keratosis \\
\hline 3 & HAM_0002730 & ISIC_0025661 & $\mathrm{bkJ}$ & histo & 80.0 & male & scalp & Benign keratosis \\
\hline 4 & HAM_0001466 & ISIC_0031633 & bkl & histo & 75.0 & male & ear & Benign keratosis \\
\hline
\end{tabular}

Figure 4.4: Characteristics of lesions

Figure 4.5 show the user interface of the system and the predicted output as the type of skin cancer. There is 91.2 accuracy achieved at epoch as 19 for the CNN model. Figure 4.6 shows the confusion matrix for 200 sample which are used in testing the model.

\section{Skin Cancer Detection}

Check whether the lesion in image is cancerous or not.
Select image to upload
\begin{tabular}{|l|l}
\hline Choose file & Browse
\end{tabular}

\section{Detect}

Prediction: Melanoma

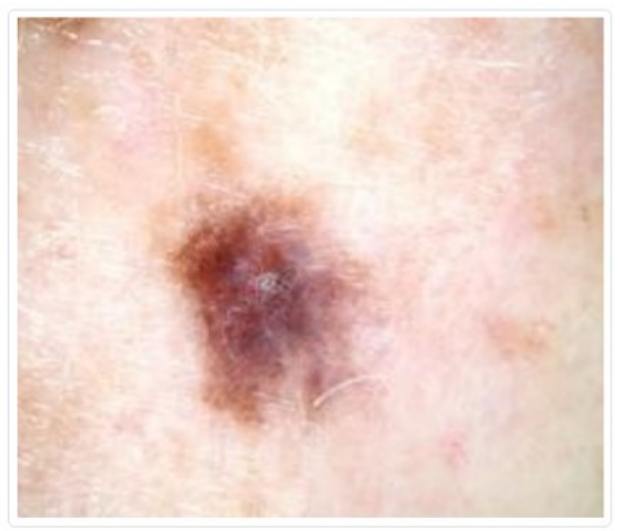

Figure 4.5: The predicted skin cancer type 


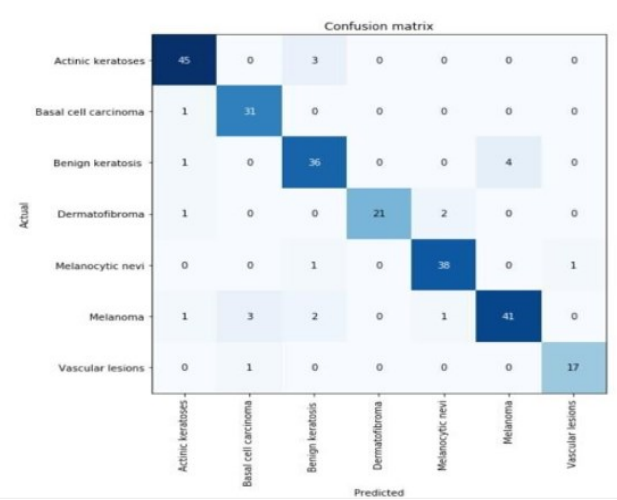

Figure 4.5: Accuracy assessment of the predicted result

\section{Conclusion}

In recent years, tremendous growth has been observed in different type of skin cancer in Asian as well as other countries. Non-invasive approaches are gaining popularity for early detection of skin cancers. A welltrained computer aided diagnosis system can correctly detect presence of skin cancer and the type of cancer. In the proposed system some pre-processing is applied on input images to enhance the quality of images and to remove hairs from those images. CNN model is utilised which could be able to correctly detect the skin cancer and classify it as one of the three types of cancer with an accuracy of $91.2 \%$. However, overall accuracy can be affected in case of dermoscopic image of dark-skinned patients. Also, the large size dermoscopic image dataset would be used further to improve the classification results.

\section{References}

[1]. World Cancer Research Fund on Skin Cancer Statistics.

https://www.wcrf.org/dietandcancer/cancertrends/skin-cancer-statistics.
[2]. World Health Organization on Climate Change and Human Health. https://www.who.int/globalchange/climate/summar y/en/index 7.html

[3]. Ichim, Loretta, and Dan Popescu. "Melanoma Detection Using an Objective System Based on Multiple Connected Neural Networks." IEEE Access 8 (2020): 179189-179202.

[4]. Demyanov, Sergey, et al. "Classification of dermoscopy patterns using deep convolutional neural networks." 2016 IEEE 13th International Symposium on Biomedical Imaging (ISBI). IEEE, 2016.

[5]. Majumder, Sharmin, and Muhammad Ahsan Ullah. "Feature extraction from dermoscopy images for an effective diagnosis of melanoma skin cancer." 2018 10th International Conference on Electrical and Computer Engineering (ICECE). IEEE, 2018.

[6]. Eltayef, Khalid, Yongmin Li, and Xiaohui Liu. "Detection of melanoma skin cancer in dermoscopy images." Journal of Physics: Conference Series. Vol. 787. No. 1. IOP Publishing, 2017.

[7]. Jain, Shivangi, and Nitin Pise. "Computer aided melanoma skin cancer detection using image processing." Procedia Computer Science 48 (2015): 735-740.

[8]. Isasi, A. Gola, B. García Zapirain, and A. Méndez Zorrilla. "Melanomas non-invasive diagnosis application based on the ABCD rule and pattern recognition image processing algorithms." Computers in Biology and Medicine 41.9 (2011): 742-755.

[9]. She, Zhishun, Y. Liu, and A. Damatoa. "Combination of features from skin pattern and ABCD analysis for lesion classification." Skin Research and Technology 13.1 (2007): 25-33.

[10]. $\mathrm{PH}^{2}$ Database. $\quad$ https://www.fc.up.pt/addi/ph2। $\%$ 20database.html 